\title{
Deliberation level of constitutional debates in Georgian Parliament
}

\author{
VLADIMERI NAPETVARIDZE, TINA TSKHOVREBADZE, \\ TAMILA NIPARISHVILI AND KRISTINA NIPARISHVILI
}

\section{sciendo}

Politics in Central Europe (ISSN: 1801-3422)

Vol. 16, No. 1

DOI: $10.2478 /$ pce-2020-0014

\begin{abstract}
In the given paper a discourse quality index (DQI) tool, rooted to criteria elaborated by Jurgen Habermas's in his discourse ethics, will be modified and used to assess the deliberation level of the 1995 Georgian Parliament. The methodology will accurately represent important principles of deliberation. Due to its focus on observable behavior and its detailed coding instructions, a discourse quality index can be a reliable measurement of the quality of political debates. The DQI for a parliamentary debate in the example of the 1995 parliament of Georgia will be illustrated in the given article. The parliamentarian debates concerning the adoption of the 1995 constitution of Georgia, according to its importance, will be taken as the specific case to be analysed. In the framework of the research, scholars will study and analyse over 200 pages of stenographic recordings of the parliamentary debates connected to the mentioned topic. The DQI score will be evaluated based on the analyses of the stenographic records.
\end{abstract}

Keywords: Deliberation, Discourse, Measurement, Parliamentary debate, Georgia, Constitution.

\section{Introduction}

The study and analysis of deliberation processes are one of the controversial aspects of political sciences. A great number of papers, scientific articles and discussions are dedicated to this component because discourse ethics and the level of deliberation has vital importance in the process of democratic development of a country since it is a necessary constituent of the political life and 
governance. The higher the degree of argument-based discussions in political organisations and state bodies of a country, the more stable and stronger is the state of democracy.

Thus, scientists are studying factors and external circumstances which can influence discourse ethics formation. Researching discourse ethics and deliberation level in developing states in the post-soviet countries, where the process of democratic transition is still ongoing (Wheatley 2017), has crucial importance. As most of these countries regained their independence only two decades ago, the consolidation and institutionalisation of the political system have not been completed yet. It is important to study these processes from the initial phase up to now, because it allows scientists to obtain a full picture of development of a political structure, thus facilitating the identification of existing drawbacks.

The purpose of this work was to consider the quality of deliberation and discourse based on the analysis of stenographic reports of the Georgian Parliamentary meetings, which would allow outlining the stages and periods of discourse quality index development and formation in Georgia. The main task of the research was to analyse the existing stenographic records, which could be evaluated by the DQI methodology.

The research aim was to analyse one of the major issues in the history of independent Georgia - the process of adopting the Constitution - in terms of discourse ethics. The conduction of the constitution-making process, the quality of discourse and the key issues identified during the constitution-making process were analysed in the research.

At the next stage of the study, the aim was to reflect the obtained results and the measurement of the deliberation level of the debates related in terms of Jurgen Habermas' discourse ethics and to elaborate the DQI index.

For the democratic development of aa country the effective operation of State and civil institutions is crucial. During the research of discourse ethics and the level of deliberation the research object is the state representative body, as the political elite with its own specific political culture is considered to have significant impacts on the process of democratic development of the country. Their debates, forms and methods of interaction, communication and attempts to reach the consensus are perceived as a possible way to define democratic processes. Thus, in the framework of the given article, a clear analysis of the events which shapes democratic development and formation in Georgia will be provided. It is possible to highlight a few important features of these processes:

1. Questions of statehood and self-determination for a country which recently regained independence;

2. How the political elite of the 1990s considered the role and place of the citizens in the political life of the country;

3. Relationship between political processes, politicians and the population. 
The text is structured into major parts among which the first (Introduction) chapter covers the research aim and the relevance of the work. The second (Background) chapter outlines the situation in Georgia that prevailed at the moment of parliamentary debates on the adoption of the Constitution and had an impact on the debate process. The Theoretical framework chapter justifies the choice of Jürgen Habermas' methodology and gives an overview of the tool for measuring a discourse quality index. The Research Methodology chapter is focused on describing coding procedure and the DQI tool, which includes seven coding categories. This chapter provides justification to the criteria, analysed in this research. The Research findings chapter provides the results of the research for each of the accessed criterion. The last chapter presents the key findings of the study and defines the main topics of the discussions.

\section{Background}

On 24 August 1995, after three months of discussions, the Georgian Parliament adopted the Constitution of Georgia, which is the legal successor of the 1921 Constitution (Georgian Parliament Archive 2018). Twenty-four parties were represented in the parliamentary plenary sessions in 1995 . In theory that suggests the pluralistic nature of the legislation process, which is one of the key values of democracy. Nevertheless, although the 1992-95 Parliament was marked by multiparty representations, the other questions were how far parliamentarians expressed their independent and individual positions, whether the body worked based on democracy, how important decisions were made, how well-founded the speeches were and whether the MPs were ready to face criticism from their opponents. To assess the dynamics of development of the Georgian Parliamentarian system, it is necessary to assess the work of the Parliament of Georgia about something as important as the adoption of the Constitution after the restoration of state independence. In 1995 after regaining independence, adoption of the Constitution became an important cornerstone for the future development of the country. However, during the constitution-adoption process, several questions were raised and opinions were divided. On the one hand, the 1995 Constitution is the legal successor of the 1921 Constitution, according to which it was mandatory to carry out the referendum in order to change the previous version of the document. On the other hand, owing to the political situation, the government was not able to hold the nationwide referendum. The reason invoked was that during that period the so-called Tskhinvali region and Abkhazia were run by self-proclaimed governments. The topic of the referendum had become the leading cause of disputes in the 1995 Parliament discussions about adopting the constitution. One group of Parliamentarians claimed that the Constitution could not be adopted with a violation of the 1921 Constitution. The other one considered that Georgia had to adopt the Constitution because 
of the international political situation. Some of the MPs believed that for years after restoration of the country's independence the adoption of the Constitution would become an important milestone in developing the Georgian State (Sarishvili, 1995). These were the main issues during the parliamentary debate but in the end the Parliament adopted the Constitution. Based on the analysis of the stenographic recordings made at parliamentary plenary sessions the team of three researchers assessed a deliberation level of the parliamentary sessions using the criteria elaborated by the group of scientists based on Jurgen Habermas' discourse quality approaches.

\section{Theoretical framework}

As it was mentioned before, over the past decade research of discourse quality index has become one of the main pillars of deliberation research, and deliberation has become a crucial component of a responsive and responsible democracy (Carpini 2004). There are various theories about deliberation studies. According to deliberation theory, political decision-making is or should be 'talk-centric' rather than 'vote-centric' (Bohman and Rehg 1997). Some scholars even think that a 'discourse is nothing that can be contained within a closed-up room but is characterized by its capacity to spread and to permeate boundaries' (Landwehr 2010).

For a more accurate picture, it is necessary to determine the meaning of the discourse itself. The main contradiction in the twentieth century was between two great thinkers - Jürgen Habermas and Michel Foucault (Stahl 2004).

Michel Foucault, defined discourse as 'ways of constituting knowledge, together with the social practices, forms of subjectivity and power relations which inhere in such knowledges and relations between them. Discourses are more than ways of thinking and producing meaning' (Arribas-Ayllon 2008). Foucault is interested in discourse as the societal process of understanding and self-definition. His research is mainly concentrated on the way discourses are organised and defines who participates, contributes and who is excluded This question of inclusion or exclusion from discourse is the central topic of his notion. The procedures that control and organize discourses are manifold. They include truth, conversational taboos, madness, doctrine, (scientific) discipline and others (Foucault 1971).

On the other hand, in Habermas' theoretical writings the concept of discourse is as central as it is in Foucault's, but it takes on a different meaning. The Theory of Communicative Action (1981a/b), arguably Habermas' most important work, explains the concept and function of discourses. Communicative action is distinguished from other types of action such as pragmatic action or strategic action, which are based on bilateral respect between participants of the process. One of the most important aspects of Habermas' approaches are an ethical side of communicative action. The background to this is the conception of humans 
as social beings who need to interact in order to survive and prosper. We need to collaborate and by employing communicative action we do so in a moral fashion.

Even today, scientist can't agree which is the best way to measure deliberation index. Throughout history we've seen many different examples of using various techniques to evaluate discourse. For example, Holzinger tried to study degree of discourse using quantitative research methods. He studied the debates regarding waste management in one of the German settlements. According to the results, he distinguished two aspects of the deliberation process - debates and negotiation. According to Holzinger, arguing occurs in most bargaining situations where bargainers seek to justify their positions even where no shared interests or generalisable reasons exist (Holzinger 2004).

Using discourse studies, Leitner tried to define which social and/or political forces determined or influenced broadcasting of Radio BBC English from 1922-1954 and ,Deutsche Rundfunksprache' radio broadcasting from 1923-1945 (Leitner 1980).

Despite different views and approaches, everyone agrees that deliberation plays a huge role in the political decision-making process. Decision-making is a process in which political actors discuss a variety of opinions, justify and evaluate their position and through a process of discourse eventually revise their initial preferences. (Habermas 1981, 1990, 1991, 1995, 1996).

Such a process of discourse improves the informational level of participants (Fishkin 1995) and therefore decisions made by decision-makers will be more legitimate (Cohen 1989).

Due to the fact that there are different approaches towards the deliberation phenomena, various scientists use different measurement instruments to evaluate the quality of discourse. In 2003 a group of scientists including Marco Steenbergen, André Bachtiger, Markus Sporndliand and Jurg Steinerbased created a tool for measuring a discourse quality index based on Jurgen Habermas' origins. Researchers defined 7 scalable components to measure the discourse quality index of an individual statement: I - Participation, II - Level of justification, III - Content of justifications, IV - Respect for the groups, V - Respect towards the demands of others, VI - Respect for counterarguments, VII - Constructive politics. The coding categories can be combined to form a scale that can serve as an overall measure of discourse quality. (Marco R. Steenbergen, André Bachtiger 2003). Thus, the DQI makes it possible to empirically research deliberation level.

\section{Research Methodology}

The study is aimed at analysing stenographic recordings made at parliamentary plenary sessions in 1995 based on the importance of the considered issue. As the Constitution is the basic document for the government and society, the 
analysis of its pre-adoption period is extremely helpful in understanding the essence of one of the main state bodies of Georgia - the Parliament. For the analysis of stenographic recordings of parliamentary plenary sessions, we used the discourse quality index tool (DQI) elaborated by the group of scientists based on Jurgen Habermas discourse ethics motion.

It became necessary to analyse stenographic recordings made at the parliamentary plenary sessions in 1995, in total 91 speeches. At the same time each of the mentioned speeches had to meet four different criteria: it should be theoretically grounded, it should tap into observable phenomena, it should be general and it should be reliable. These 91 speeches were chosen because in accordance with Habermas' method they more effectively responded to the above-mentioned criteria.

Coding proceeded in two steps. First researchers defined which speeches were relevant to the study. In general, researchers studied 200 pages of transcripts about the debates regarding the adoption of the constitution and picked out 91 speeches which could be assessed using the DQI tool.

In the second stage relevant statements were assessed using the DQI tool, which included seven coding categories. Each of the categories possesses an individual sub-assessment system:

'Participation' - This refers to a speaker's ability to participate freely in a debate. We use two codes for participation:

- 0 - Speaker is Interrupted;

- 1 - Normal participation is possible;

The first code is reserved for situations in which a speaker is interrupted. This does not include situations when a speaker is interrupted because her/his time is up. This coding category depends least on the subjective opinion of the researchers. When assessing this aspect, codes of the three researchers were the same in overall.

'Level of justification' - During the debates each speech is assessed by the following codes:

- 0 - no justification; A speaker only says that X should or should not be done, but no reason is given. This code also applies if a conclusion is merely supported with illustrations.

- 1 - inferior justification; A speaker agrees on one of the positions outlined in the agenda but uses general and vague arguments.

- 2 - qualified justification; A linkage is made as to why one should expect that $\mathrm{X}$ contributes to or detracts from $\mathrm{Y}$.

- 3 -sophisticated justification; In this case, at least two reasons are given, either to justify the demand of the speaker. 
'Content of justifications' includes several sub criteria:

- (0) Explicit statement - concerning group interests: A speaker mentions one or more groups or Constituencies in a speech;

- (1) Neutral Statement - A speaker doesn't mention constituency or group of interests or the common good;

- (2a) Explicit statement of the common good in utilitarian terms - A speaker mentions the common good in utilitarian terms, including such terms in a speech such as the universal well-being for all citizens, etc.

- (2b) Explicit statement of the common good in terms of the difference principle - A speaker mentions the common good in terms of the difference principle, with reference to helping specific groups of a society.

'Respect towards the groups'

- (0) Neutral - The speech includes only negative statements about the groups;

- (1) Implicit Respect - There is no negative or explicit positive statements in a speech;

- (2) Explicit Respect - The speech contains at least one explicitly positive statement about the groups.

'Respect towards the demands of others' - This indicator uses the same codes as the group respect indicator. This is a specific criterion and to asses it we need to discuss the demand of the speakers and therefore evaluate the responses to these demands.

- Code 0 - Negative attitude;

- Code 1 - Implicit respect;

- Code2 -Explicit respect;

'Respect towards the counterarguments' - This type of respect is coded only if there are provided some arguments and the counterarguments responding to them. There are four codes to measure respect toward counterarguments:

(0) Counterarguments ignored: A speaker ignores existing counterarguments;

(1) Counterarguments included but degraded: A speaker acknowledges a counterargument, but degrades it by making a negative statement about it;

(2) Counterarguments included - neutral: A counterargument is acknowledged but there are no positive or negative responses.

(3) Counterarguments included and valued: A counterargument is acknowledged and is valued. 
'Constructive politics' - This indicator measures a so-called consensus building process and it is assessed by 3 codes:

(0) Positional politics: Speakers stay on their positions. There is no compromise, reconciliation or consensus building;

(1) Alternative proposal: A speaker makes an alternative proposal. In such cases, the proposal does not fit the current debate, although it may be taken up in a different debate;

(2) Mediating proposal: A speaker makes a mediating proposal that fits the agenda.

In the framework of the given study, researchers assessed discourse quality index by the above-mentioned criteria, results obtained during the coding procedure were assigned points. The research undertaken allowed researchers to measure the quality of deliberation during these debates. However, two of the above-mentioned criteria were impossible to consider in the debate and, therefore, they were not included in the study.

Independent coding will serve as the basis for the reliability statistics reported in this paper, since it depends on the subjective judgments of the experts, which in turn increase the probability of biased results. For example measuring an indicator such as the level of justification is based on the subjective opinions of the researcher, he/she defines which speech can be assumed as sophisticated presentation with high-level argumentations or the opposite. In order to avoid inaccuracy, three researchers separately assessed each of the speeches. Eventually, researchers presented the results to each other and finally came to a joint decision. If none of the researchers altered their position, each of their codes would have been shown separately. This method is implemented to obtain the most accurate possible results.

After the speeches were assessed according to the DQI indicator and results were identified, the group of Georgian researchers tried to present obtained data in percentages. From the mentioned seven categories, scientists used five categories, which explicitly showed the quality of deliberation.

Although in the study the stenographic recordings were analysed in accordance with the seven criteria elaborated by Jurgen Habermas to obtain a discourse quality index, Georgian researchers used only five criteria (participation; level of justification; respect for the groups; respect for counterarguments; constructive politics), which better described a culture of debates. The remaining two criteria were assessed under the study, although this data was not used while elaborating the final discourse quality index.

For example, if only $70 \%$ of the speakers were given the opportunity to finish their speeches without an interruption, then the index of Participation would be $70 \%$ which is equal to 7 points, from the maximum of 10 points. The results will be summarised and the level of deliberation during the debates about the adoption of the 1995 Constitution will be defined. 
Although many theorists believe that deliberative politics leads to better outcomes, there is no consensus on this matter, with some arguing vociferously that a connection between deliberation and just outcomes cannot be presumed (Sanders, 1997; Gutmann and Thompson, 2002). It should be pointed out at the outset that this is a measurement paper. We lack the space to investigate the impact of discourse quality on political outcomes.

Besides, a technical shortcoming of the research is that the analysis is conducted according to the stenographic recordings, where it cannot be identified whether the speaker is joking or speaking ironically.

We finalised the results and held the discussions about speech assessment. The data below is the result of the analysis of stenographic recordings conducted by three researchers on the basis of the discourse quality index.

It should be noted that not all the speeches were assessed by the researchers, since some of them were very short.

\section{Research findings}

As mentioned earlier, the DQI consists of seven coding categories and each of these categories possesses an individual assessment system.

\section{The First criterion - 'Participation'}

During the debates only 65 from 91 speakers, respectively, were given an opportunity to end their speeches without interruptions. Thus, in only $71 \%$ of cases interruption was not noted (Table 1). We can conclude that every third speech was interrupted, and this is a violation of the ethics of dialog and debate. As an example of interrupted speech, we can discuss the statement of the deputy Luiza Shakiashvili: 'Perhaps, our future Parliament will be staffed with people far worse than present one, for example (buzz, inaudible). Now you are joking even laughing but...'1

Since there are no audio recordings of the plenary sessions, the note in the stenographic reports represent that the conference room was noisy, and the speech could not be recorded. Therefore, the speech is considered interrupted and assessed by code 0 .

\section{The Second criterion - 'Level of justification'}

During the discussions about the status of the document, Zurab Jvania in his remarks made rational argumentation on the necessity of concrete ' $\mathrm{X}$ action'

1 Stenographic recording from the Parliament archive. Georgian Parliament session. Speaker - L. Shakiashvili - Page 33. 22 August 1995. 
in order to achieve 'Y outcome'. In his speech, he explained why it was necessary to define the status of the document at first and only after that to discuss protective mechanisms of it: 'Ordinary law, organic law, even a constitutional law, doesn't need such strong protective mechanisms, we are discussing now. So, I agree that first, we should define on what type of document we are working on? Is it the constitution, or some kind legislative act?'2

In the given example the reader can see that there is a linkage between the $Y$ reason (to discuss a protective mechanism) and the $\mathrm{X}$ action (which is discussion about the type of document). Researchers agreed that Jvania's statement was logical and had a linkage with the main purpose of the parliamentary discussion.

From 91 speeches about the adoption of the Constitution only 28 speeches respectively were satisfactory justified, the remaining 63 were not justified (Table 2). The arguments were not linked to the matter... The results clearly expose that most of the reports were not well-argued. Most of them were ill-founded, which decreases the quality of deliberation.

\section{The Third criterion - 'Content of justifications'}

For illustration we provide part of one of the speeches, where a member of the Parliament speaks about the greatest good for the greatest number: 'The Constitution must not be developed for a person, a group or an organization. It must be adopted for the country and for all people living in the country and believing this country to be their homeland. I agree with my colleagues that claim that Constitution must be regulated. I share the opinion that in today's environment it is wrong to adopt the Constitution against the law. However, there is an old saying „if the child has not been born and has never been young, he will never grow up". Therefore, despite the many shortcomings, I support the adoption of the Constitution'. ${ }^{3}$ In his speech, MP Goderdzishvili explained why he supported the adoption of the Constitution despite many shortcomings. He was speaking from the perspective of Georgian society, underlining the fact that adoption of the Constitution would be beneficial for all Georgians, therefore he supported it.

During the discussion about the adoption of the Constitution, 41 speeches out of 91 accordingly addressed the protection of public interests. This code considers various associations, consisting of several persons. Based on the figures presented above, we can conclude that most of the speeches addressed the common good. In other words, the deputies used public interest to enforce their own arguments.

2 Stenographic recording from the Parliament archive. Georgian Parliament session. Speaker - Zurab Jvania - Page 4. 22 August 1995.

3 Stenographic recording from the Parliament archive. Georgian Parliament session. Speaker - G. Goderdzishvili - Page 13. 22 August 1995. 


\section{The Forth criterion - 'Respect towards the groups'}

From the total of 91 speeches respectively the negative attitude towards the group was explicit in ten speeches, and 30 speeches represented a pronounced respect. In nine speeches respectively, no sign of negative or positive attitude was revealed.

\section{The Fifth criterion - 'Respect towards the demands of others'}

This code is applied to the reports, representing positive attitude towards the speeches of other deputies or the agenda. We can consider as an example the speech of K. Garibashvili, Democratic Party deputy, who explicitly expressed his positive attitude towards the Constitution adoption process: 'Here we are 200 people and it is Impossible that 200 people had no claims against adopting this document as our Constitution. I, myself, don't believe that it will be a bad decision, on the contrary, it will be a good one'.

In this speech we can see a positive attitude towards the key requirement - to adopt the document as a new Constitution. Thus, this speech is assessed with code 2 .

Respect towards the demands of others - codes of the above mentioned criterion are the exact analogs of the codes of the previous criteria This code is applied to the reports, depending on the content of the speech.

This indicator was recorded in 78 speeches from 91 speeches which accounted for $44 \%$ of the total number of speeches. In other speeches, respect towards the demands of others was not expressed.

Thus, it can be seen that there is no big difference between positive and negative attitude, indicating that an almost equal number of speakers expressed both positive and negative opinions in relation to the claims on the agenda or arising during the debates.

\section{The Sixth criterion - 'Respect for counterarguments'}

Below is an example of the speech in which speakers acknowledged the counterarguments and changed their opinion. For this example, we refer to the report of the deputy N. Natadze, where he speaks about Givi Lominadze's argumentation in a positive manner: 'I heard Mr. Givi Lominadze's who insisted that our Constitution must be adopted under the presence in Parliament Abkhaz deputies. I believe this argument to be an ultimate. That is why I will vote in favor of this proposal'. ${ }^{4}$

4 Stenographic recording from the Parliament archive. Georgian Parliament session. Speaker - N. Natadze - Page 11. 22 August 1995. 
Based on the specifics of the criterion this indicator was recorded the least number of times: 31 cases from a total of 91 speeches.

In view of the foregoing it is apparent that the deputies were intolerant towards criticism regarding their speeches. In 32 cases only five deputies expressed a positive attitude towards comments or criticism regarding their previous speeches. In $72 \%$ of the total number of cases the attitude towards counterarguments was starkly negative: counterarguments were overlooked or ignored or received poor evaluation. The data represents the positional nature of the debates.

\section{The Seventh criterion - 'Constructive politics'}

Based on the specificity of the category this indicator was recorded the least number of times: from 91 speeches on the adoption of the Constitution the indicator presented in only 36 cases of them, 15 speeches respectively included a negative attitude and the speakers stayed on their position without compromise. As for alternative proposals, 21 deputes introduced their initiation which didn't fit the agenda, but could be negotiated. For example, Sarishvili offered to postpone the adoption process and instead of a new Constitution, use already existing codes: 'I think there is one more option. We can leave the "the state government code", as our main law, which has almost the same power, like the constitution. If we don't adopt a new „election code“, we could use an existing one. This will give us an additional 3 years...'

Nevertheless, Parliament adopted this document with the support of a majority of deputies.

An attempt to represent the percentage in figures made by Georgian researchers is given below. From the mentioned seven categories, scientists used five, which explicitly shows the quality of deliberation and democratic values. The received results are awarded with points from 1 to 10 . In the end, the maximum score is 50 .

The criteria are the following I - participation, II - level of justification, III content of justification, IV - respect for the groups, V - respect towards the demands of others, VI - respect for counterarguments, VII - constructive politics. The percentage of the data will be determined, and points will be awarded accordingly from 1 to 10 .

Considering the participation, the percentage of uninterrupted speeches is 70, therefore a category received 7 points. Considering the level of justification, only $30 \%$ of speeches are recognized as argued and thus this criterion is assessed with 3 points. Considering the respect for the groups, explicit respect was recorded in $35 \%$ of cases and thus it is assessed with 4 points. Considering the respect for counterarguments, only $28 \%$ of speeches contained a positive attitude, so this category received 3 points accordingly. Considering the con- 
structive policy from 36 speeches, which were against the agenda, 15 (42\%) of them stayed on their position and voted against adoption of the document, and 21 MP's (58\%) who were against the current agenda initiated negotiable proposals, and this criterion can be assessed with 6 points.

In general, from 50 possible points, the level of deliberation of the Georgian Parliament during the debates over the adoption of the Constitution was 23, to convert this data into percentage, we get the following result: the debates over adoption of the Constitution of Georgia fulfills only $46 \%$ of high-level deliberative discourse ethics (Table N1).

\section{Table 1:}

\begin{tabular}{|l|c|}
\hline Criteria & Maximum point 10 \\
\hline participation & 7 \\
\hline level of justification & 3 \\
\hline respect for the groups & 3 \\
\hline respect for counterarguments & 6 \\
\hline constructive politics & $23=46 \%$ \\
\hline Overall points & 3 \\
\hline
\end{tabular}

\section{Conclusions}

Since political science is still a new discipline for Georgia, there are many important historical events that need to be studied and analysed, in order to get a clearer picture of the political processes taking place in Georgia during the transition period. This study is an attempt to assess the political 'teenage period' of independent Georgia from different perspectives.

This rticle is an attempt to display the percentage of deliberation in figures made by the group of Georgian scientists working on this problem. From the seven criteria of the DQI index, Georgian scientists used the five which explicitly reflected the quality of deliberation (Participation; Level of justification; Respect for the groups; Respect for counterarguments; Constructive politics;) in order to measure the level of deliberation in Georgian Parliament during the discussion on the Constitution adoption process.

Thus, the study proved that the quality of debates in the Georgian legislature didn't meet the condition. Below are provided key findings of the study: 
- Georgian politicians were easily swayed by the opinion of the strong political leaders.

- They were least focused on argued, rational and logical aspects of the discussion, by which consensus is achieved.

- If we compare the quality of Georgian political deliberation with Habermas' characteristics and the results, expected if they present, it can be said that the democratic processes in 1990s Georgia unfolded with mistakes and impediments.

- Legislators lacked strong political and civic culture, which is one of the main factors of a country's democratic development.

- They were not concerned with the role of citizens' participation in the decision making process. - During the debates mutual respect was rarely shown.

Using the DQI indicator in the research process made it possible together with an evaluation of the deliberation process in numbers, to show the importance of these discussions.

The adoption of the 1995 Constitution was one of the important steps in a statehood formation process of Georgia after regaining independence in 1991. Discussion and evaluation of stenographic analysis of debates related to the adoption of the Constitution made it possible together with the evaluation of the quality of debate, to define the main topics of the discussion.

On the one hand, a group of the deputies believed that Georgia had not been ready to adopt the Constitution and the document on which the discussions were held hadn't to be the Constitution of the country but the act of the Constitution. On the other hand, another group of MPs' had considered that Georgia needed the Constitution.

Both sides had their own argument. Some of the MP's that considered that the document should not be granted the status of the Constitution were appealing on Chapter 17 of the 1921 Constitution, where the rules for further revision of the Constitution were defined. The mentioned chapter covered 5 articles, two of them - articles 146 and 147 - became the subject of a special dispute:

Article 146 - A proposal for the revisal of the Constitution can only be heard in Parliament six months after the deposition of such a proposal.

Article 147 - A proposal or plan for the partial or entire revisal of the Constitution can only be adopted by a majority of two-thirds of the members of Parliament. This proposal only comes into force after it has received the approval of the people.

A group of the deputies stated that the new Constitution would have violated the main principles of the 1921 Constitution; in particular, adoption of the new Constitution without holding the referendum was a violation of the article. 
Article 147 from the 1921s Constitution, according to which revisal of the Constitution could only be adopted after it has received the approval of the people.

In 1995 Georgia could not conduct a referendum because of the simple reason that after 1993 the Georgian government de-facto lost control over Abkhazia and the Tskhinvali region and therefore it was impossible to conduct a survey in every region of the country.

Consequently, the Constitution of 1995 was based on the results of the 1991 referendum, the main topic of which was re-gaining the independence of Georgia. ${ }^{5}$

Most of the MP's believed that despite the resistance, Georgia had to adopt the Constitution, as it would have been a significant step forward for the state development process. Furthermore, according to their assumptions, after the adoption of the Constitution, Georgia could gain more international support and this fact could positively reflected on the issue of conflict resolution.

Finally, on August 24, 1995, Georgia adopted the Constitution that is still functioning today. It turned out that discussion on the Constitution adoption started in February 1995. It should be noted that the Constitution was adopted in conditions of urgency. That is reflected in the fact that the debates about this topic were held on the parliamentary meetings on 22 March and on 22, 23, 24 August 1995 and on 24 August the Parliament adopted the Constitution.

\section{References}

Arribas-Ayllon, M., - Walkerdine, V. (2008): Foucauldian discourse analysis. The Sage handbook of qualitative research in psychology. 91-108.

Bohman, J. (Ed.). (1997): Deliberative democracy: Essays on reason and politics. MIT press.

Carpini, M. X. D. - Cook, F. L. - Jacobs, L. R. (2004): Public deliberation, discursive participation, and citizen engagement: A review of the empirical literature. Annu. Rev. Polit. Sci. 7: 315-344.

Cohen, J. (1989): Deliberation and democratic legitimacy.1997, 67-92.

Fishkin, James S. (1995): The voice of the people. Public opinion and democracy.

Foucault, Michel (1971): L'ordre du discours.

Georgian Parliament (2018): Constitution of Georgia; Retrieved from http://www.parliament. ge/ge/kanonmdebloba/constitution-of-georgia-68.

Gutmann, A. - Thompson, D. (2002): Deliberative democracy beyond process. Journal of Political Philosophy 10(2): 153-174

Habermas, J. - Ben-Habib, S. (1981): Modernity versus postmodernity. New German Critique (22): 3-14.

5 Departments of the Supreme Council of the Republic of Georgia. (09 April.1991). Act of Restoration of State Independence of Georgia. Retrieved from : https://matsne.gov.ge/en/document/ view/32362?publication=0; 
Habermas, J. (1990): Der philosophischediskurs der moderne. MIT Press.

Habermas, J. - Habermas, J. (1991): The structural transformation of the public sphere: An inquiry into a category of bourgeois society. MIT press.

Habermas, J. (1995): Paradigms of law. Cardozo L. Rev. 17: 771.

Habermas, J. (1996): The European nation state. Its achievements and its limitations. On the past and future of sovereignty and citizenship. Ratio juris 9(2): 125-137.

Holzinger, K. (2004): Bargaining through arguing: an empirical analysis based on speech act theory. Political Communication 21(2): 195-222.

Landwehr, C. (2010): Discourse and Coordination: Modes of Interaction and their Roles in Political Decision-Making. Journal of Political Philosophy 18(1): 101-122.

Leitner, G. (1980): BBC English and Deutsche Rundfunksprache: a comparative and historical analysis of the language on the radio. International Journal of the Sociology of Language 1980(26): 75-100.

Sanders, L. M. (1997): Against deliberation. Political theory 25(3): 347-376.

Stahl, B. C. (2004): Whose discourse? A comparison of the Foucauldian and Habermasian concepts of discourse in critical IS research. AMCIS 2004 Proceedings, 538.

Steenbergen, M. R., Bächtiger, A., Spörndli, M., \& Steiner, J. (2003): Measuring political deliberation: A discourse quality index. Comparative European Politics 1(1): 21-48.

Stenographic recording from the Parliament archive. Georgian Parliament session. Speaker Sarishvili - Page 27. 22 August 1995.

Stenographic recording from the Parliament archive. Georgian Parliament session. Speaker - L. Shakiashvili - Page 33. 22 August 1995.

Stenographic recording from the Parliament archive. Georgian Parliament session. Speaker Zurab Jvania - Page 4. 22 August 1995.

Stenographic recording from the Parliament archive. Georgian Parliament session. Speaker - G. Goderdzishvili - Page 13. 22 August 1995.

Stenographic recording from the Parliament archive. Georgian Parliament session. Speaker - N. Natadze - Page 11. 22 August 1995.

Wheatley, J. (2017): Georgia from national awakening to Rose Revolution: delayed transition in the former Soviet Union. Routledge.

Vladimeri Napetvaridze is a, Ph.D. candidate of Tbilisi State University and Assistant-researcher of Institute of Political Sciences of Ilia State University. E-mail: lado.napetvaridze@gmail.com

Tina Tskhovrebadze is, Ph.D. candidate of Tbilisi State University and Assistant-researcher of Institute of Political Sciences of Ilia State University. E-mail: tikotskhovrebadze@gmail.com 
Tamila Niparishvili is Assistant-researcher of Institute of Political Sciences of Ilia State University.

Kristina Niparishvili is Assistant-researcher of Institute of Political Sciences of Ilia State University. 